\title{
An archaeological radiocarbon database for southern Africa
}

\author{
Emma Loftus ${ }^{1,2}$, Peter J. Mitchell ${ }^{3}$ and Christopher Bronk Ramsey ${ }^{4}$ \\ ${ }^{1}$ McDonald Institute for Archaeological Research, University of Cambridge, Downing Street, \\ Cambridge, CB2 3ER, United Kingdom and Merton College, University of Oxford, Merton \\ Street, Oxford, OX1 4JD, United Kingdom \\ 2 School of Archaeology, University of Oxford, 36 Beaumont Street, Oxford, OX1 2PG, UK \\ and School of Geography, Archaeology and Environmental Studies, University of the \\ Witwatersrand, PO Wits 2050, South Africa \\ ${ }^{3}$ Research Laboratory for Archaeology and the History of Art, University of Oxford, 1 South \\ Parks Road, Oxford OX1 3TS, United Kingdom
}

\begin{abstract}
An online open-access database of published radiocarbon dates from southern African archaeological contexts is presented. The database is integrated with the calibration, Bayesian modelling and mapping functionality of the widely-used OxCal software. As with other regional radiocarbon databases, this database will greatly help to document and analyse chronological trends across the subcontinent. We present two archaeological case studies that demonstrate the utility of both this database and its integration with OxCal, comparing the temporal distribution of radiocarbon dates in two archaeologically well-investigated regions and assessing the timing of Middle to Later Stone Age technological turnover across the subcontinent.

\section{Introduction}

Radiocarbon dating has a long history in southern Africa, beginning with the establishment of a radiocarbon laboratory in Pretoria in 1967 that took the lead in dating the now familiar features of the region's prehistoric sequence. Its achievements included showing that the origins of the Middle Stone Age (MSA) lie beyond the limits of the radiocarbon method, that the Later Stone Age (LSA) extends past 20,000 years ago, and that pastoralists, soon followed by Iron Age Bantu communities, were present in southern Africa from c. 2000 years ago, long before the date promoted by the apartheid government's propaganda (Vogel \& Beaumont 1972; Beaumont \& Vogel 1972; Mason et al. 1973).
\end{abstract}

To begin with, African archaeological radiocarbon dates were largely disseminated through annotated date-lists and review articles in the Journal of African History (e.g. Fagan 1961, 1969). As their number increased, researchers working in distinct areas of Africa produced regional syntheses of the broad chronological trends (e.g. Maggs 1977; Hall \& Vogel 1980; Parkington \& Hall 1987). However, these studies often provided only minimal details about the radiocarbon measurement itself and its archaeological context, routinely omitting details such as a site's precise location. Date lists in Radiocarbon generally provided more detail about the radiocarbon measurement itself, including laboratory protocols and stratigraphic associations (e.g. Vogel and Marais 1971; Vogel and Visser 1981; Vogel et al. 1986), but typically did not aim to contextualise dating results within a broader archaeological understanding. Globally, the publication of radiocarbon dates within archaeological studies continues under widely varying standards, with reports frequently omitting important pieces of information, including the unique laboratory identifier, the material dated, and even the uncalibrated radiocarbon age itself. Omitting these details can, of course, render the data unusable for inclusion in future synthetic analyses. 
The aggregation and modelling of large chronological datasets is a powerful method for detecting large-scale demographic and cultural transitions. Several researchers have applied "dates as data" approaches to southern Africa's archaeological record, beginning with Janette Deacon's (1974) assessment of the small set of Later Stone Age dates then available by physiographic and vegetation regions to note the effects of changing climate (especially water availability) on the distribution of human occupations across the terminal Pleistocene and Holocene. Two decades later, Lyn Wadley (1993) tackled a larger dataset to reconstruct demographic fluctuations through the MSA and Pleistocene LSA, something subsequently extended to Holocene hunter-gatherers (Mitchell 1997) and Iron Age farming communities (Vogel 1995; Vogel \& Fuls 1999). When and how domesticated animals and ceramic technologies first arrived in southern Africa in pastoralist contexts has also been explored (Sadr 2015; Sadr \& Sampson 2006).

Recently, the development of specialist software and methodological approaches for handling spatial and chronological data has led to increasingly sophisticated attempts to quantitatively model radiocarbon data in various archaeological settings around the world. Large research programmes have emerged to compile and analyse radiocarbon dates (e.g. Williams \& Smith 2013; Gayo et al. 2015; Martindale et al. 2016). And yet, such applications are still rare in southern Africa (although see Russell et al. 2014; Bousman and Brink 2017), partly because of a general scarcity of chronological expertise in southern Africa and due to a relative paucity of dates for constraining archaeological events over the long time-spans and broad landscapes of southern African prehistory. Currently, radiocarbon dates for the region are scattered amongst publications spanning decades of research, which makes it challenging to track changing chronological interpretations of a single site, never mind an entire region.

As has been understood now for some time in other parts of the world, including Australia (Williams \& Smith 2013) and the southern Andes (Gayo et al. 2015), a first step towards the routine application of radiocarbon data to wide-ranging archaeological questions is the development of a centralised repository for radiocarbon measurements and associated publications, something we present here. In addition, the Southern African Radiocarbon Database (SARD) provides full integration with the open-access radiocarbon calibration and modelling software OxCal (Bronk Ramsey 1995), including mapping capabilities and spatial analytical tools. Beyond the vital task of cataloguing published radiocarbon dates, this functionality enables researchers to undertake simple and more complex analyses of radiocarbon data at a range of scales. Below, we present SARD and describe the analytical possibilities it offers in conjunction with the OxCal software by reference to two broad archaeological research questions.

\section{The Southern African Radiocarbon Database: compilation and design of SARD}

To date, the Southern African Radiocarbon Database comprises published dates selected from more than 350 papers, books, and reports, spanning more than 50 years of archaeological research. At its launch, SARD (https://c14.arch.ox.ac.uk/sadb/db) holds some 2500 archaeological radiocarbon dates (Figure 1) from over 600 sites (Figure 2). South African dates currently dominate the database $(>75 \%)$, reflecting the preponderance of South African researchers in the region and the role of the Pretoria radiocarbon laboratory. Indeed, c. $60 \%$ dates are from that laboratory alone, while nearly half the total number of dates included in SARD are from the last two thousand years (Figure 1). Certain essential criteria were deemed necessary for inclusion in the database, with other non-essential information gathered where reported (Table 1$)$. 


\begin{tabular}{lll}
\hline & Criteria & Description \\
\hline \multirow{4}{*}{ Essential } & Site name & Unique site name, as in publication \\
\cline { 2 - 3 } & Location & Decimal degrees longitude and latitude (WGS 84) \\
\cline { 2 - 3 } & Laboratory code & $\begin{array}{l}\text { Identifies the laboratory where the measurement was } \\
\text { made and acts as a unique identifier }\end{array}$ \\
\cline { 2 - 3 } & Date type & AMS or conventional \\
\cline { 2 - 3 } & Uncalibrated date and error & Years BP \\
\cline { 2 - 3 } & Material class & Material with restricted options \\
\cline { 2 - 3 } & Reference & $\begin{array}{l}\text { Generally, a published research article detailing the } \\
\text { measurement and its archaeological associations }\end{array}$ \\
\cline { 2 - 3 } Non-essential & Stratigraphic or other & $\begin{array}{l}\text { May be as specific as possible to pinpoint sample } \\
\text { the widely reab-periods: restricted options based on }\end{array}$ \\
\cline { 2 - 3 } & contextual details & $\begin{array}{l}\text { Restricted options, including rock-shelter, shell } \\
\text { midden, rock art, human burial, etc. }\end{array}$ \\
\cline { 2 - 3 } & Site type & $\begin{array}{l}\text { Biomes (SANBI vegetation map; Mucina \& } \\
\text { Rutherford 2006) and main season of precipitation } \\
\text { (summer, winter or year-round)s }\end{array}$ \\
\cline { 2 - 3 } & $\begin{array}{l}\text { For human dietary and palaeoenvironmental } \\
\text { assessment, often included with radiocarbon results }\end{array}$ \\
\cline { 2 - 3 } & $\delta^{13} \mathrm{C}$ & $\begin{array}{l}\text { E.g. date considered unreliable, alternative } \\
\text { archaeological categorisation, unusual material }\end{array}$ \\
\cline { 2 - 3 } & Comments & \\
\hline
\end{tabular}

\section{Essential criteria}

Site names are as given in the literature, with individual uncalibrated dates distinguished by the unique radiocarbon laboratory identification code. Dates are also characterised as measured by either AMS or conventional (i.e. counting) radiocarbon methods, a broad indicator of precision and quality (Linick et al. 1989). Locations are as reported in site publications when possible, but in many instances only approximate (or conflicting) location information is provided (e.g. to degrees and minutes only, or simply indicated on a map). While the coordinates in the current database are appropriate for regional-scale spatial analyses, they are not guaranteed to be correct at a highly localised scale (and, consequently, are not likely to be helpful in finding the actual location on the ground). The broad class of material dated (bone, charcoal, marine shell, etc.) is considered essential for inclusion, not least to characterise potential radiocarbon reservoir effects. Finally, each date also requires a reference, typically a published research article. Importantly, each date can be associated with every publication that cites the date, allowing site interpretations to be updated and tracked with further research.

\section{Non-essential criteria}

Further non-essential information for each entry includes contextual details, such as stratigraphic layer for intra-site chronological modelling and type of site (e.g. human burials, rockshelters, shell middens). Another variable intended to help with preliminary analyses is archaeological association, which poses a challenge for standardising the terms used to identify 
key cultural phases. We have adopted the most widely recognised and accepted frameworks, namely the tripartite division between the Middle Stone Age, Later Stone Age, and Iron Age, with subdivisions for the Later Stone Age (Early Later Stone Age, Robberg, Oakhurst, Wilton, and Ceramic Later Stone Age; Lombard et al. 2012) and Iron Age (Early and Late Iron Age; Huffman 2007). This system may, of course, overlook certain archaeological episodes or communities, or force a categorisation where more fluid definitions would be more appropriate, so caution is required when using this search term. Finally, two broad environmental variables, vegetation biome and rainfall seasonality (summer, winter and year-round rainfall zones), are derived for sites within South Africa, Swaziland, and Lesotho from the South African National Biodiversity Institute's Vegetation Map (Mucina \& Rutherford 2006) and the WorldClim Global Climate Date precipitation dataset (Fick \& Hijmans 2017).

A key goal in designing the database was to facilitate exploratory analyses within the OxCal software environment, using both the essential and the non-essential associated information. A "filter" function allows certain of these broad categories to be selected. Once the desired data are chosen, they can be exported as a .csv spreadsheet for inclusion in a table or other analytical software. The database is designed to be continuously updated via a Certain response fields have restricted options to guide the submitter and limit the profusion of single entry categories within the database.

\section{Integration of SARD with OxCal}

SARD is hosted by the Oxford Radiocarbon Accelerator Unit (ORAU) at the University of Oxford and is accessible via login credentials for the open-access OxCal software (currently v. 4.3). Developed over the past two decades, OxCal is a widely used software package for the calibration of radiocarbon dates and Bayesian analysis of chronological data. Additionally, the ORAU website hosts several databases, including that of the ORAU laboratory itself (https://c14.arch.ox.ac.uk/database/db.php), the Egyptian Radiocarbon Database (Bronk Ramsey et al. 2010), the INTIMATE and RESET palaeoenvironmental databases (Bronk Ramsey et al. 2014; 2015), and now SARD. SARD is fully integrated with the calibration and analytical tools of OxCal and allows data to be transferred easily from the database to the OxCal modelling environment. The integration of SARD with OxCal is an important feature in ensuring the database's longevity and accessibility as part of an institutionally supported and widely used web resource. Moreover, OxCal provides powerful tools for the integration and analysis of radiocarbon data.

\section{Calibration, Bayesian modelling and aggregation}

As a primary analytical step, OxCal facilitates the rapid and easy calibration of radiocarbon dates incorporated from the SARD database. Calibration is an essential step for accurately estimating true calendar ages, yet its practice in the southern African-specific literature, in particular, is variable, with uncalibrated ages still routinely referenced and compared. When exporting dates from SARD into OxCal, the default calibration curve is SHCal13, the most recent curve for the Southern Hemisphere (Hogg et al. 2013). Given that marine derived samples are identified in the database, the marine calibration curve, Marine13, with an appropriate regional offset can be applied where necessary (Dewar et al. 2012; Reimer et al. 2013).

Once selected dates are imported to the OxCal environment, it is simple to begin incorporating stratigraphic, quality, and other details for Bayesian and Kernel Density Estimation modelling 
of site and regional data. Models of radiocarbon dates can range from the straightforward (for example, simply aggregating dates via a Sum command: Bronk Ramsey 2001) to the very complex, with numerous nested levels of Bayesian stratigraphic priors and outlier weightings across several sites. A valuable function of Bayesian modelling methods, especially as implemented in OxCal, is the detection of chronological outliers. Many of the radiocarbon dates included in the database were obtained many decades ago, using analytical methods that have since been superseded. Consequently, discrepancies are possible between these older data and newly acquired radiocarbon dates for particular sites and archaeological events. Modelling these combined datasets in OxCal can identify likely outliers via the assessment of agreement indices produced by OxCal or through the application of formal outlier models (Bronk Ramsey 2009).

A new tool to highlight here, useful for aggregation of larger numbers of radiocarbon dates, is the KDE_Model function (Bronk Ramsey 2017). Kernel Density Estimation (KDE) models can be applied to large sets of related dates to characterise the overall age range and distribution of the dated events visually in much the same way as summed distributions. However, they are more successful at removing high frequency variability that can make summed probability distributions difficult to interpret.

\section{Mapping}

SARD is integrated with the mapping functionality of OxCal, allowing sites to be easily visualised on the landscape as a preliminary analytical step. The OxCal mapping tool relies upon the Google Maps service, with five base maps: road; terrain; satellite; hybrid; and a plain scalable vector graphic (SVG) of the continental outline. Within the database, sites can be easily filtered and mapped, with analytical tools including spatial KDE analysis to identify clusters of related sites.

More sophisticated mapping and spatial analysis of radiocarbon date distributions through time is notoriously difficult, largely due to the complexity of visualising both time (especially on radiocarbon timescales) and space in standard GIS applications (Green 2011). A common approach is the utilisation of time slices, but these require onerous data processing and are relatively inflexible. OxCal can map the changing probabilities of calibrated radiocarbon dates (as opposed to sites) through time, producing a continuous series of timeslices at the desired resolution (50 years, 1000 years, etc.) (Bronk Ramsey \& Lee 2013). The output of OxCal posterior distributions, including Boundaries or KDE distributions, can be geotagged and visualised via the mapping tool.

\section{Archaeological examples}

\section{Radiocarbon dates from the southernmost coast of South Africa and Lesotho}

Two regions of southern Africa that have witnessed intense archaeological investigation are its southernmost coast (defined here as $19-27^{\circ} \mathrm{E}, 33-35^{\circ} \mathrm{S}$ and informally referred to in the literature as the 'southern Cape') and the highlands of Lesotho and the regions immediately surrounding them (defined here as $26.5-30^{\circ} \mathrm{E}, 28.5-31^{\circ} \mathrm{S}$ ) (Figure 3). Both regions boast long records of hunter-gatherer occupation, with well-dated rock-shelter deposits spanning the entirety of the LSA sequence, if not beyond. Recently, archaeologists have contrasted cultural and technological events from coastal locations and the continental interior (Loftus et al. 2016, in prep.; Pargeter et al. 2017, 2018). Figure 4 contrasts the KDE models of all dates for each 
region, highlighting large differences between them in the frequency of radiocarbon dates across the late Pleistocene and Holocene. Lesotho and its surrounds feature slightly more dates $(n=298)$ from more sites $(n=42)$ than the southern Cape (253 dates, 37 sites). The latter's radiocarbon record shows few dates across the late Pleistocene, with a gradual increase from 15 kcalBP peaking in the early-mid Holocene c. 7 kcalBP. Thereafter, the number of radiocarbon dates from this region decreases slightly, before peaking again in the late Holocene. Dates across Lesotho and its surrounds show a more punctuated pattern, with repeated clusters across the late Pleistocene and two notable peaks $c$. 10 and $2.5 \mathrm{kcalBP}$ separated by a decline across the mid-Holocene. A more dramatic increase in dates towards the present (i.e. >2000 years) is observed than in the southern Cape, possibly reflecting the displacement of hunter-gatherers in the latter region by low visibility, open-air focused herding communities (Arthur 2008).

The differences between the KDE distributions reflect well-known features of the two archaeological records. The Maloti Mountains of highland Lesotho and the adjoining uKhahlamba-Drakensberg Escarpment collectively form southern Africa's highest region and today experience some of the subcontinent's coldest conditions, with frequent snowfalls during winter. Given considerably cooler temperatures under glacial conditions, it is plausible that the region was unsuitable for habitation during the height of the Last Glacial Maximum (c. $22.3 \pm 3.6 \mathrm{ka}$ ) an interpretation borne out by the scarcity of archaeological deposits dated to this period (Pargeter et al. 2017; Stewart \& Mitchell 2018). The KDE distribution also shows a peak in radiocarbon dates between 12 and 9 kcalBP, perhaps indicating reoccupation after the end of the Younger Dryas stadial. There is a marked subsequent decrease in dates from the early to mid-Holocene, a period of climate-driven demographic decline across the subcontinent's interior (Deacon 1974).

Familiar features of the regional archaeological record are likewise evident in the KDE model of dates from the southern Cape. Their steady increase along its coast largely reflects rising sea-levels across the terminal Pleistocene, as the coastline came to assume its modern configuration, areas currently offshore were drowned, and people relocated further inland (for a general discussion of this process, see Compton, 2011). However, early Holocene conditions in the southern Cape clearly also accommodated relatively large populations at this time, as a small decrease in radiocarbon dates is observable here too after 7 kcalBP, despite the region's insulation from the worst effects of water stress observed elsewhere across the subcontinent by coastal resources and a year-round rainfall climate (Sealy 2016).

\section{The Middle to Later Stone Age transition}

Two broad periods intersect with the period of radiocarbon applicability in southern Africa, namely the Middle and Later Stone Ages. Broadly, Final MSA assemblages are characterised inter alia by large triangular flakes produced on Levallois cores and bifacial or unifacial points, whereas the earliest "true" LSA industry, the Robberg, features abundant unretouched bladelets and other microlithic elements (Lombard et al. 2012). Informal "transitional" assemblages are recognised at a few sites between the two. These "Early LSA" occurrences frequently contain an unstandardised microlithic element that distinguishes them from the preceding Final MSA, but may also reflect mixing of Middle and Later Stone Age assemblages. The nature of the technological transition across the period c. 40-20 ka is thus currently only poorly understood (Mitchell 2008), something compounded by the scarcity of well-dated long sequences throughout the subcontinent. 
Figure 5 shows the KDE model distributions for all radiocarbon dates tagged as relating to either the Final MSA ( $=92)$, Early LSA $(n=95)$ or Robberg $(n=106)$ technological complexes in SARD. The number of Final MSA dates increases sharply just before $40 \mathrm{kcalBP}$ and decreases steadily until 25 kcalBP. Conversely, the number of Early LSA dates increases gradually from 35 kcalBP to a peak c. 25 kcalBP, just after the last Final MSA dates are recorded. An earlier concentration of Early Later Stone Age dates c. $40 \mathrm{kcalBP}$, in apparent antiphase with the Final Middle Stone Age distribution, all come from the site of Border Cave, which contains an anomalously early, but nevertheless intensively and tightly dated, assemblage attributed to the LSA (d'Errico et al. 2012; Villa et al. 2012; cf. Pargeter et al. 2016 for discussions of this designation). In contrast to the gradual decline in the Final MSA distribution, the Early LSA distribution declines quite abruptly prior to $20 \mathrm{kcalBP}$. The earliest dates of Robberg assemblages overlap with those of the Early LSA assemblages for approximately 5000 years, but increase markedly after 17 kcalBP.

The compilation of dates from SARD can also be mapped to give a spatial perspective on the Middle to Later Stone Age transition. Figure 6 shows the individual probability distributions of calibrated radiocarbon dates associated with the Final MSA, Early LSA, and Robberg industries across southern Africa in 2000-year time slices, from 34 to $20 \mathrm{kcalBP}$. The size of the circle reflects the likelihood of that date occurring within that time slice. The maps clearly show that Early LSA assemblages are earliest in the east of the subcontinent, appear in the west only after 26 kcalBP, and are virtually absent along the well-researched southern Cape coast. They also show that Robberg assemblages occur first there and in highland Lesotho.

\section{Future developments and conclusion}

The design and ongoing maintenance of SARD allows for the incorporation of new features and larger datasets. Given the extreme time depth of the southern African archaeological record, a valuable addition will be the inclusion of non-radiocarbon absolute ages derived from methods such as luminescence and uranium-series dating. OxCal must identify and handle nonradiocarbon dates differently from radiocarbon dates to avoid calibrating ages that do not require it. While modelling non-radiocarbon ages in OxCal is possible, an automated arrangement for incorporating such dates from SARD still needs to be established. This is one of several refinements that we plan to develop. Others include the capability to search by bounding coordinates and to import new dates directly via the user interface.

The Southern African Radiocarbon Database aggregates many decades of archaeological research and serves as a valuable repository of radiocarbon dates and associated publications. The simple analyses demonstrated here reflect only some aspects of the subcontinent's archaeological record, but promise further insights with deeper investigation of the database. Other topics that could be explored include the expansion of microlithic technologies during the early and mid-Holocene (Deacon 1974), interaction between hunter-gatherers and farming communities (Sadr \& Sampson 2006), and the long-term demographic history of southern Africa's drylands compared with those elsewhere in the southern hemisphere (Barberena et al. 2017). In all these fields and others, a substantial advantage of SARD's implementation is its integration with OxCal, software specifically designed for the analysis of radiocarbon probability data. We believe that this will also help to ensure the database's long-term maintenance and viability as a permanent research tool for investigating the southern African past. 


\section{References}

ARTHUR, C. 2008. The archaeology of indigenous herders in the Western Cape of South Africa Southern African Humanities 20: 205-20. https://journals.co.za/content/nmsa_sah/20/1/EJC84794.

BarberenA, R., J. McDonAlD., P.J. Mitchell. \& P. Veth. 2017. Archaeological discontinuities in the southern hemisphere: A working agenda Journal of Anthropological Archaeology 46: 1-11. https://www.sciencedirect.com/science/article/pii/S0278416516301167.

BEAUMONT, P.B. \& J.C. VOGEL. 1972. On a new radiocarbon chronology for Africa south of the Equator: Part 2 African Studies 31: 155-82. https://www.tandfonline.com/doi/pdf/10.1080/00020187208707381.

BOUSMAN, C.B. \& J.S. BRINK. 2017. The emergence, spread, and termination of the Early Later Stone Age event in South Africa and southern Namibia Quaternary International, December 6. https://www.sciencedirect.com/science/article/pii/S1040618217309771.

BRONK RAMSEY, C. 1995. Radiocarbon calibration and analysis of stratigraphy: the OxCal program Radiocarbon 37: 425-30.

— 2001. Development of the radiocarbon calibration program Radiocarbon 43: 355-63. https://www.cambridge.org/core/product/identifier/S0033822200038212/type/journal_ar ticle.

- 2009. Dealing with outliers and offsets in radiocarbon dating Radiocarbon 51: 1023-45.

— 2017. Methods for summarizing radiocarbon datasets Radiocarbon 59: 1809-33. https://www.cambridge.org/core/product/identifier/S0033822217001084/type/journal_ar ticle.

Bronk Ramsey, C., P. Albert., S. Blockley., M. Hardiman., C. Lane., A. Macleod., I.P. Matthews., R. Muscheler., A. PAlmer. \& R.A. StAFF. 2014. Integrating timescales with time-transfer functions: a practical approach for an INTIMATE database Quaternary Science Reviews 106: 67-80. https://www.sciencedirect.com/science/article/pii/S0277379114002091.

Bronk Ramsey, C., M.W. DeE., J.M. Rowland., T.F.G. Higham., S.A. Harris., F. Brock., A. Quiles., E.M. WiLD., E.S. MARCUS. \& A.J. SHORTLAND. 2010. Radiocarbon-based chronology for dynastic Egypt. Science 328: 1554-57. http://www.ncbi.nlm.nih.gov/pubmed/20558717.

Bronk Ramsey, C., C.S. LANE., V.C. SMith. \& A.M. Pollard. 2015. The RESET tephra database and associated analytical tools Quaternary Science Reviews 118: 33-47. https://www.sciencedirect.com/science/article/pii/S0277379114004466\#bib11.

BRONK RAMSEY, C. \& S. LEE. 2013. Recent and planned developments of the program OxCal Radiocarbon 55: 720-30. https://www.cambridge.org/core/product/identifier/S0033822200057878/type/journal_ar ticle.

COMPTON, J.S. 2011. Pleistocene sea-level fluctuations and human evolution on the southern coastal plain of South Africa Quaternary Science Reviews 30: 506-27. http://linkinghub.elsevier.com/retrieve/pii/S0277379110004439.

D’ERrico, F., L. BACKWELl., P. Villa., I. DegANO., J.J. LUCEJKO., M.K. BAMFORD., T.F.G. HighAM. \& P.B. BEAUMONT. 2012. Early evidence of San material culture represented by organic artifacts from Border Cave, South Africa Proceedings of the National Academy of Sciences of the United States of America 109: 13214-19. http://www.pnas.org/content/109/33/13214.short.

DEACON, J. 1974. Patterning in the radiocarbon dates for the Wilton/Smithfield complex in southern Africa South African Archaeological Bulletin 29: 3. 
http://www.jstor.org/stable/3887932?origin=crossref.

DEWAR, G.I., P.J. REIMER., J.C. SEALY. \& S. WoODBORNE. 2012. Late-Holocene marine radiocarbon reservoir correction $(\{$ Delta $\} \mathrm{R})$ for the west coast of South Africa The Holocene 22: 1481-89. http://hol.sagepub.com/content/22/12/1481.short.

FAGAN, B.M. 1961. Radiocarbon Dates for Sub-Saharan Africa Journal of African History 2: 137. http://www.journals.cambridge.org/abstract_S002185370000219X.

- 1969. Radiocarbon Dates for Sub-Saharan Africa: VI Journal of African History 10: 149. http://www.journals.cambridge.org/abstract_S0021853700009336.

FICK, S.E. \& R.J. HiJMANS. 2017. WorldClim 2: new 1-km spatial resolution climate surfaces for global land areas International Journal of Climatology 37: 4302-15. http://doi.wiley.com/10.1002/joc.5086.

GAYO, E.M., C. LATORRE. \& C.M. SANTORO. 2015. Timing of occupation and regional settlement patterns revealed by time-series analyses of an archaeological radiocarbon

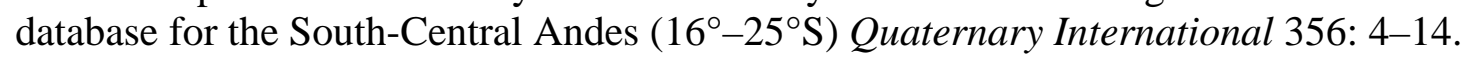
https://www.sciencedirect.com/science/article/pii/S1040618214007496.

GreEN, C. 2011. It's about time: temporality and intra-site GIS, in E. Jerem, F. Redo, \& V. Szeverenyi (ed.) Proceedings of the 36th CAA Conference 2008: 213-18. Budapest: Archaeolingua. http://proceedings.caaconference.org/files/2008/CD28_Green_CAA2008.pdf.

HALL, M. \& J.C. VOGEL. 1980. Some recent radiocarbon dates from Southern Africa Journal of African History 21: 431.

http://www.journals.cambridge.org/abstract_S0021853700018673.

Hogg, A.G., Q. HuA., P.G. BlackWell., M. NiU., C.E. BuCK., T.P. GuILDERSON., T.J. HeAton., J.G. PALmeR., P.J. Reimer., R.W. ReimeR., C.S.M. TuRnEY. \& S.R.H. ZIMMERMAN. 2013. SHCal13 southern hemisphere calibration, 0-50,000 years cal BP Radiocarbon 55: 1889-1903.

https://journals.uair.arizona.edu/index.php/radiocarbon/article/view/16783.

HufFMAN, T.N. 2007. Handbook to the Iron Age. University of KwaZulu-Natal Press.

LinicK, T.W., P.E. DAmON., D.J. Donahue. \& A.J.T. Jull. 1989. Accelerator mass spectrometry: The new revolution in radiocarbon dating Quaternary International 1: 16. https://www.sciencedirect.com/science/article/pii/1040618289900049.

Loftus, E., J.C. SEALY. \& J.A. LEe-Thorp. 2016. New radiocarbon dates and Bayesian models for Nelson Bay Cave and Byneskranskop 1: implications for the South African Later Stone Age sequence Radiocarbon 58: 365-81. http://journals.cambridge.org/abstract_S0033822216000126.

LOMBard, M., L. WADley., J. DeAcon., S. WurZ., I. PARsons., M. MohaPI., J. SWART. \& P.J. MitCHELL. 2012. South African and Lesotho Stone Age sequence updated (I) South African Archaeological Bulletin 67: 120-44. http://scholar.google.com/scholar?hl=en\&btnG=Search\&q=intitle:SOUTH+AFRICAN+ AND+LESOTHO+STONE+AGE+SEQUENCE+UPDATED+(+I+)\#5.

MAGGS, T. 1977. Some recent radiocarbon dates from eastern and southern Africa Journal of African History 18: 161.

http://www.journals.cambridge.org/abstract_S0021853700015486.

Martindale, A., R. Morlan., M. BetTs., M. Blake., K. Gajewski., M. Chaput., A. MASON. \& P.M. VERMEERSCH. 2016. Canadian Archaeological Radiocarbon Database (CARD 2.1). http://www.canadianarchaeology.ca/help.

Mason, R.J., M. KlapwiJK., R.G. Welbourne., B.H. SANDElowsky. \& T. MAGgs. 1973. Early Iron Age settlement of southern Africa South African Journal of Science 69: 32426.

MitCHELL, P.J. 2008. Developing the archaeology of marine isotope stage 3 South African 
Archaeological Society Goodwin Series 10: 52-65. http://www.jstor.org/stable/10.2307/40650019.

MuCINA, L. \& M. RuTHERFORD. 2006. The vegetation of South Africa, Lesotho and Swaziland. Pretoria: South African National Biodiversity Institute.

Pargeter, J., E. Loftus., A. Mackay., P.J. Mitchell. \& B.A. Stewart. 2018. New ages from Boomplaas Cave, South Africa, provide increased resolution on late/terminal Pleistocene human behavioural variability Azania: Archaeological Research in Africa 53: 156-84. https://www.tandfonline.com/doi/full/10.1080/0067270X.2018.1436740.

PARgeter, J., E. LofTus. \& P.J. MitChelL. 2017. New ages from Sehonghong rock shelter: Implications for the late Pleistocene occupation of highland Lesotho Journal of Archaeological Science: Reports 12: 307-15. https://www.sciencedirect.com/science/article/pii/S2352409X16308100.

Pargeter, J., A. MACKay., P.J. Mitchell., J.J. SheA. \& B.A. StewArt. 2016. Primordialism and the 'Pleistocene San' of southern Africa Antiquity 90: 1072-79. https://www.cambridge.org/core/product/identifier/S0003598X16001009/type/journal_a rticle.

PARKINGTON, J.E. \& M. HALL. 1987. Patterning in recent radiocarbon dates from southern Africa as a reflection of prehistoric settlement and interaction Journal of African History 28: 1. http://www.journals.cambridge.org/abstract_S002185370002939X.

Reimer, P.J., E. BARD., A. BAyliss., J.W. BeCK., P.G. BlaCKWEll., C.B. RAMSEY., C.E. BuCK., H. ChENG., R.L. EdWARds., M. FriedriCh., P.M. GrOOTES., T.P. Guilderson., H. Haflidison., I. Hajdas., C. Hatté., T. Heaton., D.L. Hoffmann., A.G. HogG., K.A. Hughen., K. Kaiser., B. Kromer., S.W. Manning., M. Niu., R. Reimer., D.A. Richards., E.M. ScotT., J.R. Southon., R.A. StAfF., C. Turney. \& J. PliCht. 2013. IntCal13 and Marine13 radiocarbon age calibration curves 0-50,000 years cal BP Radiocarbon 55: 1869-1887. http://researchcommons.waikato.ac.nz/handle/10289/8955.

Russell, T., F. SilvA. \& J. STEELE. 2014. Modelling the spread of farming in the Bantuspeaking regions of Africa: an archaeology-based phylogeography PLoS ONE 9: e87854. http://dx.plos.org/10.1371/journal.pone.0087854.

SADR, K. 2015. Livestock First Reached Southern Africa in Two Separate Events. PloS one 10: e0134215.

http://journals.plos.org/plosone/article?id=10.1371/journal.pone.0134215.

SADR, K. \& C.G. SAMPSON. 2006. Through thick and thin: early pottery in southern Africa Journal of African Archaeology 4: 235-52. http://www.africanarchaeology.de/index.php?page_id=154\&journal_id=2\&pdf_id=13.

SEALY, J.C. 2016. Cultural Change, Demography, and the Archaeology of the Last $100 \mathrm{kyr}$ in Southern Africa, in S. Jones \& B.A. Stewart (ed.) Africa from MIS 6-2: Population Dynamics and Paleoenvironments. Dordrecht: Springer.

StewART, B.A. \& P.J. MitChELL. 2018. Late Quaternary palaeoclimates and humanenvironment dynamics of the Maloti-Drakensberg region, southern Africa Quaternary Science Reviews 196. Pergamon: 1-20. https://www.sciencedirect.com/science/article/pii/S0277379118301148.

Villa, P., S. Soriano., T. Tsanova., I. Degano., T.F.G. Higham., F. D’Errico., L. BACKWEll., J.J. LuCEJKo., D. ComAS. \& P.B. BeAumont. 2012. Border Cave and the beginning of the Later Stone Age in South Africa Proceedings of the National Academy of Sciences of the United States of America 109: 13208-13. http://www.pnas.org/content/109/33/13208.short.

VogeL, J.C. 1995. The temporal distribution of radiocarbon dates for the Iron Age in southern Africa South African Archaeological Bulletin 50: 106. 
http://www.jstor.org/stable/3889059?origin=crossref.

475 Vogel, J.C. \& P.B. BEAUMONT. 1972. Revised radiocarbon chronology for the Stone Age in South Africa Nature 237: 50-51. http://www.nature.com/doifinder/10.1038/237050a0. Vogel, J.C. \& A. FuLS. 1999. Spatial distribution of radiocarbon dates for the Iron Age in southern Africa South African Archaeological Bulletin 54: 97. http://www.jstor.org/stable/3889287?origin=crossref.

Vogel, J.C., A. Fuls. \& E. VISSER. 1986. Pretoria radiocarbon dates III Radiocarbon 28: 1133-72.

VogeL, J.C. \& M. MARAIS. 1971. Pretoria radiocarbon dates I Radiocarbon 13: 378-94. https://www.cambridge.org/core/product/identifier/S003382220000850X/type/journal_a rticle.

VogeL, J.C. \& E. ViSSER. 1981. Pretoria Radiocarbon Dates II Radiocarbon 23: 43-80. https://www.cambridge.org/core/product/identifier/S0033822200037462/type/journal_ar ticle.

WADLEY, L. 1993. The Pleistocene Later Stone Age south of the Limpopo River Journal of World Prehistory 7: 243-96. http://link.springer.com/10.1007/BF00974721.

WiLliams, A. \& M. SMith. 2013. AustArch3: A database of 14C and luminescence ages from archaeological sites in southern Australia Australian Archaeology 76: 103. http://www.academia.edu/download/31336099/Williams_and_Smith_Austarch_3_2013. pdf. 
Figure 1. SARD: histogram of the entire uncalibrated dataset of c. 2550 dates (left) and inset 497 of dates less than $10 \mathrm{kBP}$ (right).
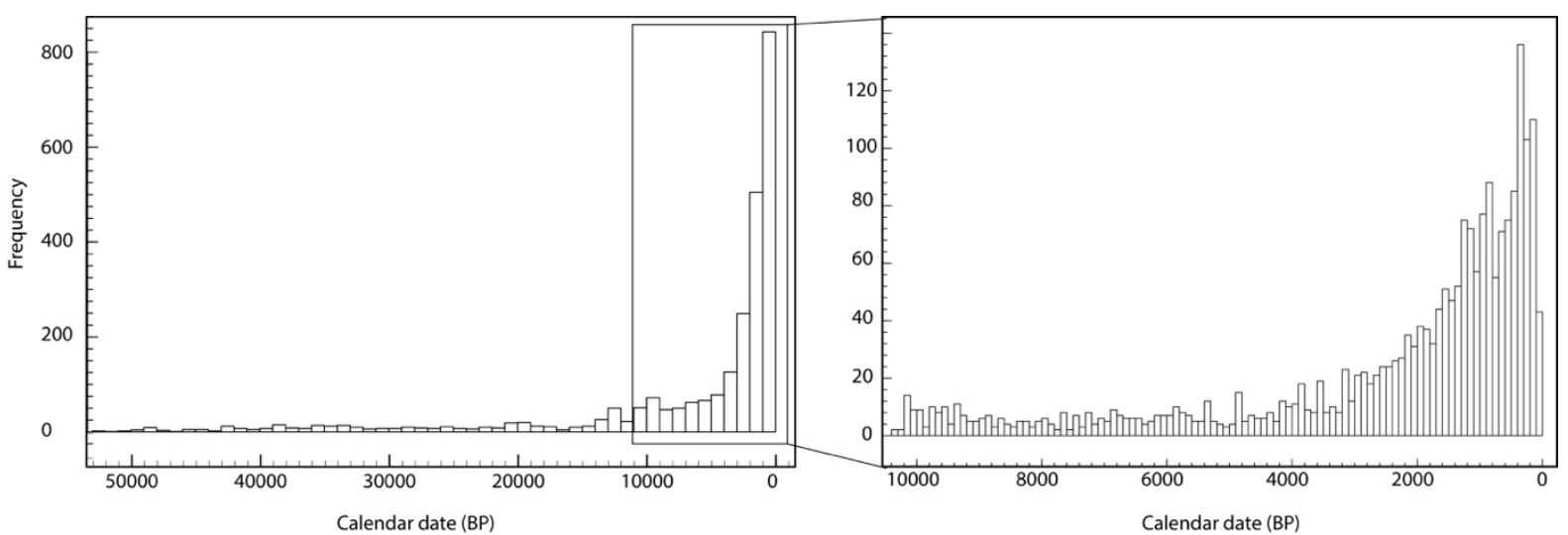

Figure 2. Distribution of radiocarbon-dated sites across southern Africa currently included in 500 SARD.

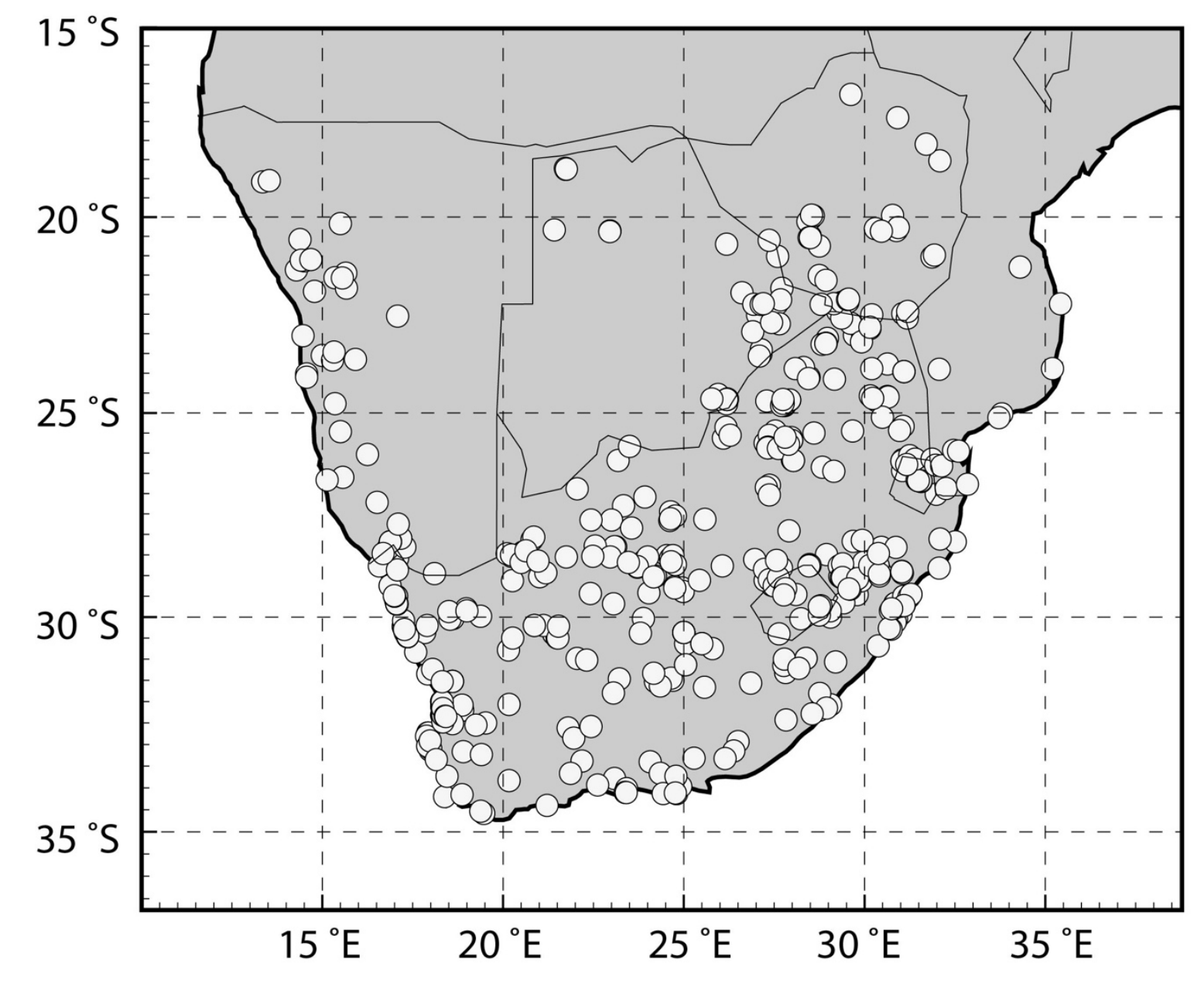


503 Figure 3. Southern Africa indicating sites in SARD from the southern Cape and Lesotho and 504 its surrounds.

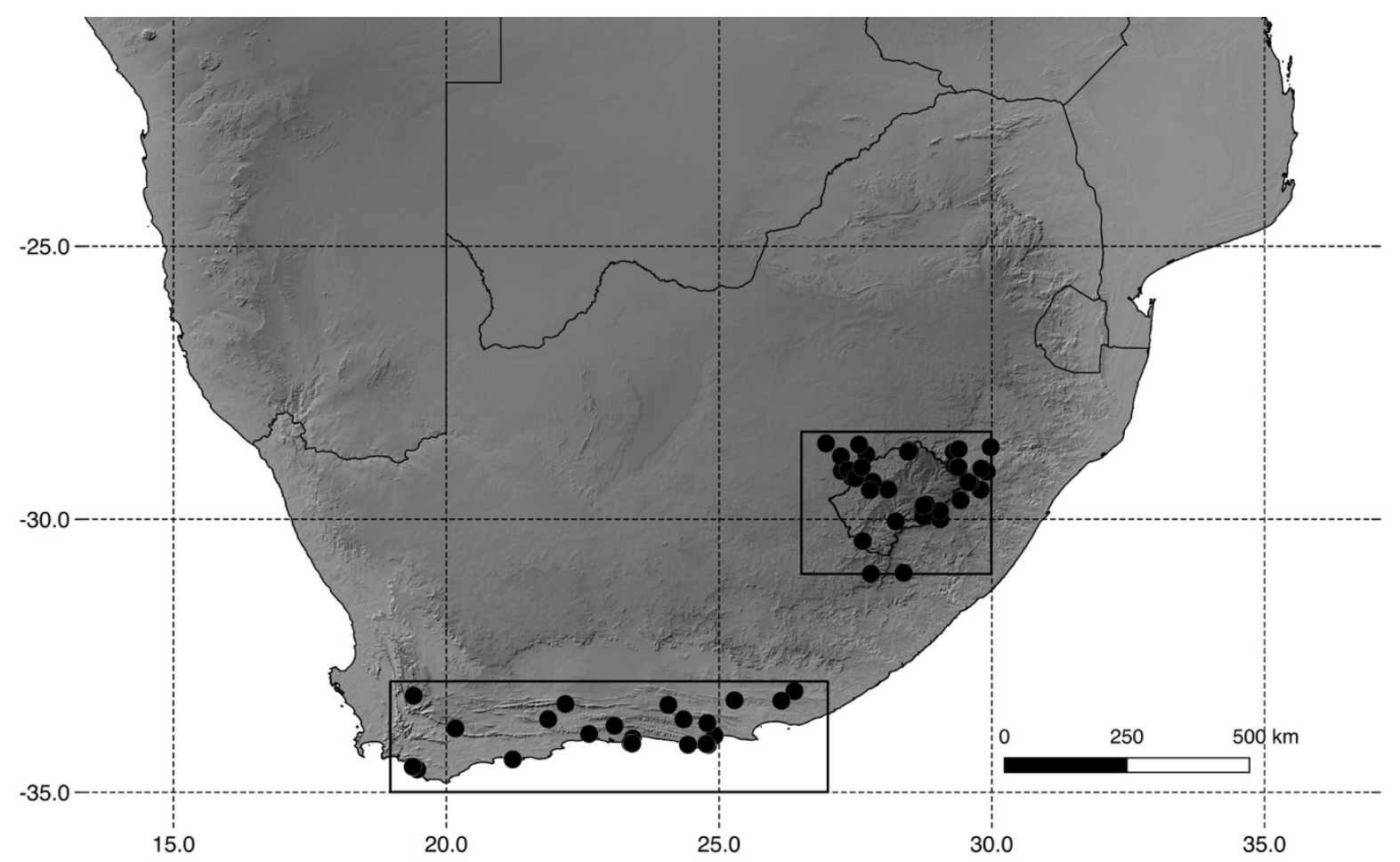


Figure 4. KDE-modelled distributions (blue line) for all radiocarbon dates from the southern

508 Cape and from Lesotho and surrounding regions. Radiocarbon determinations appear in red, 509 the SHCal13 calibration curve in blue, and the summed distribution in grey. Calibrated ages 510 are shown as grey crosses, modelled ages as black crosses.

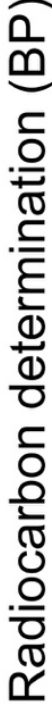
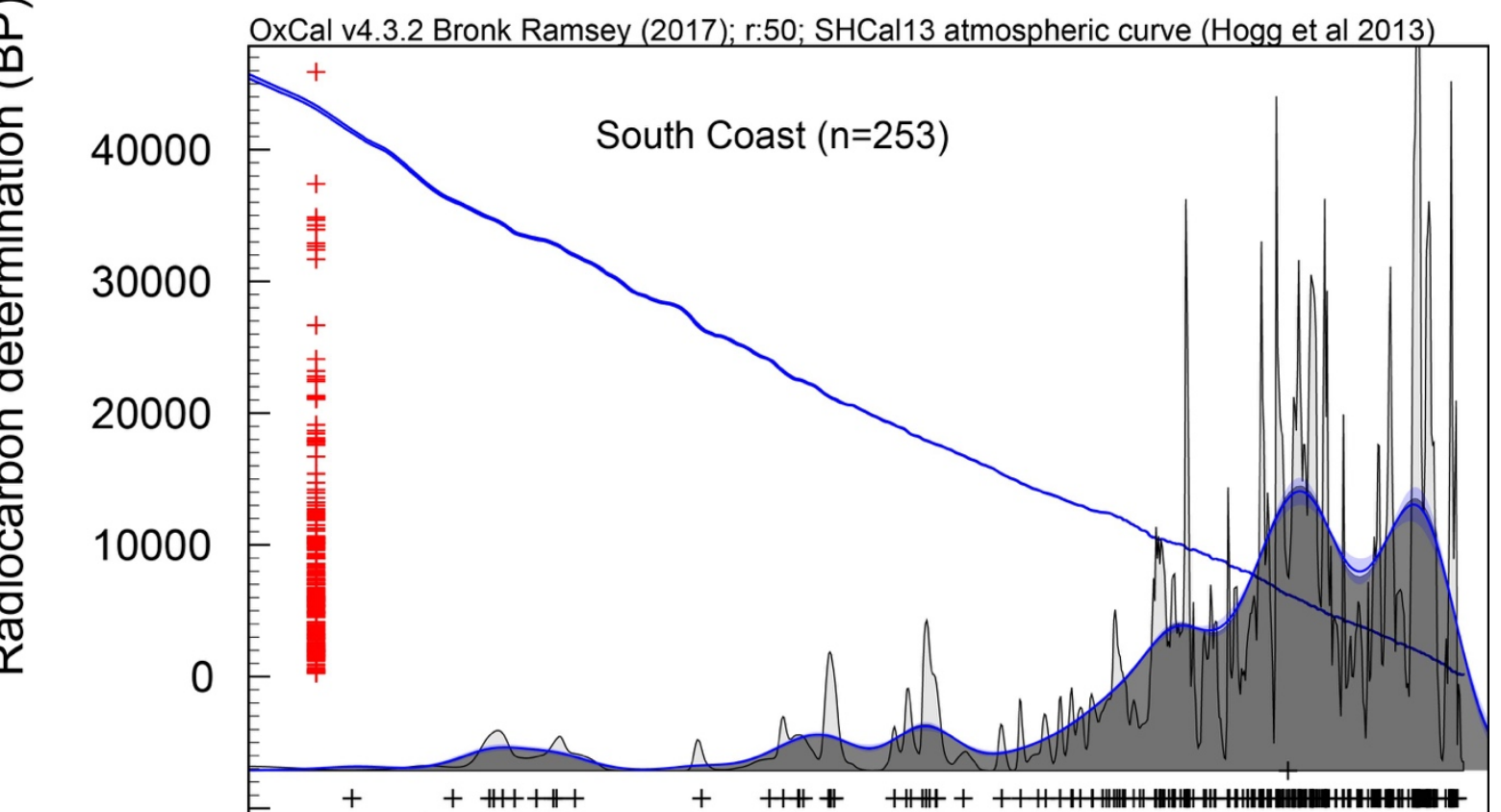

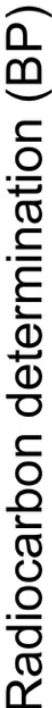

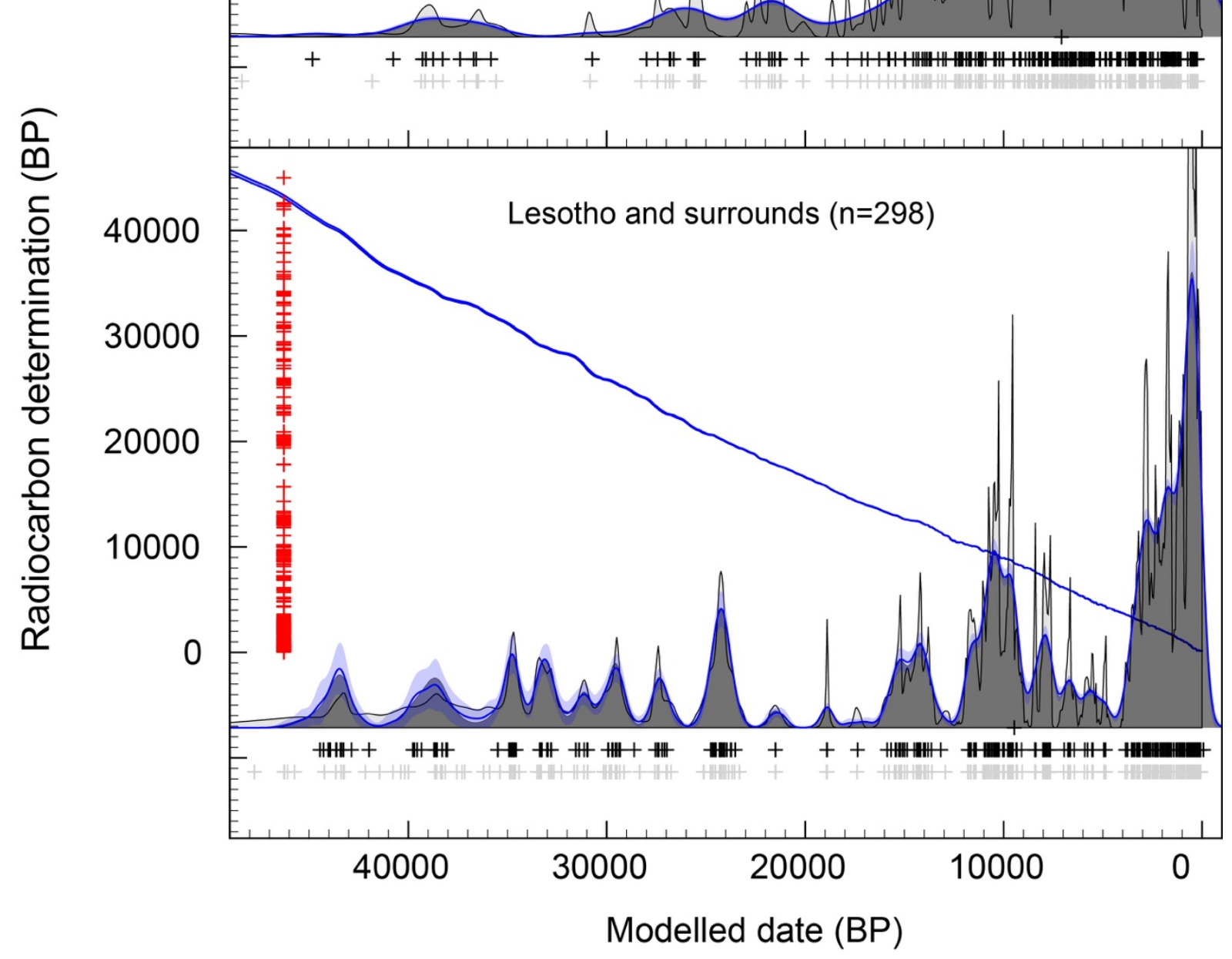


513 Figure 5. KDE models for all Final MSA, Early LSA, and Robberg dates in SARD.

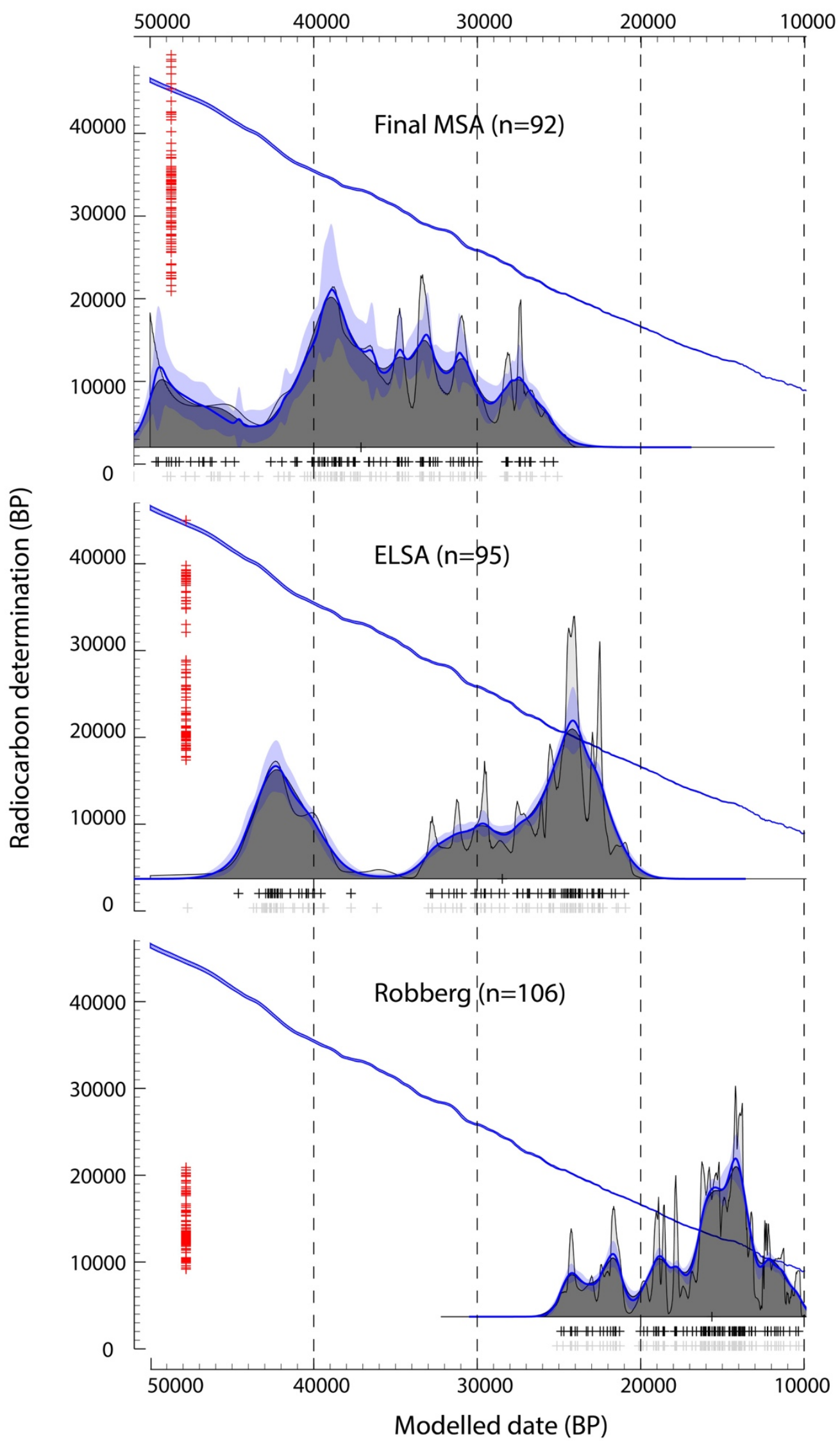


515 Figure 6. Time slice maps of calibrated radiocarbon dates for the Final MSA (red), Early LSA 516 (blue), and Robberg (green) constructed using the OxCal mapping feature. Circle size reflects 517 the likelihood of the calibrated age range for that date lying within the time range of that time 518 slice.
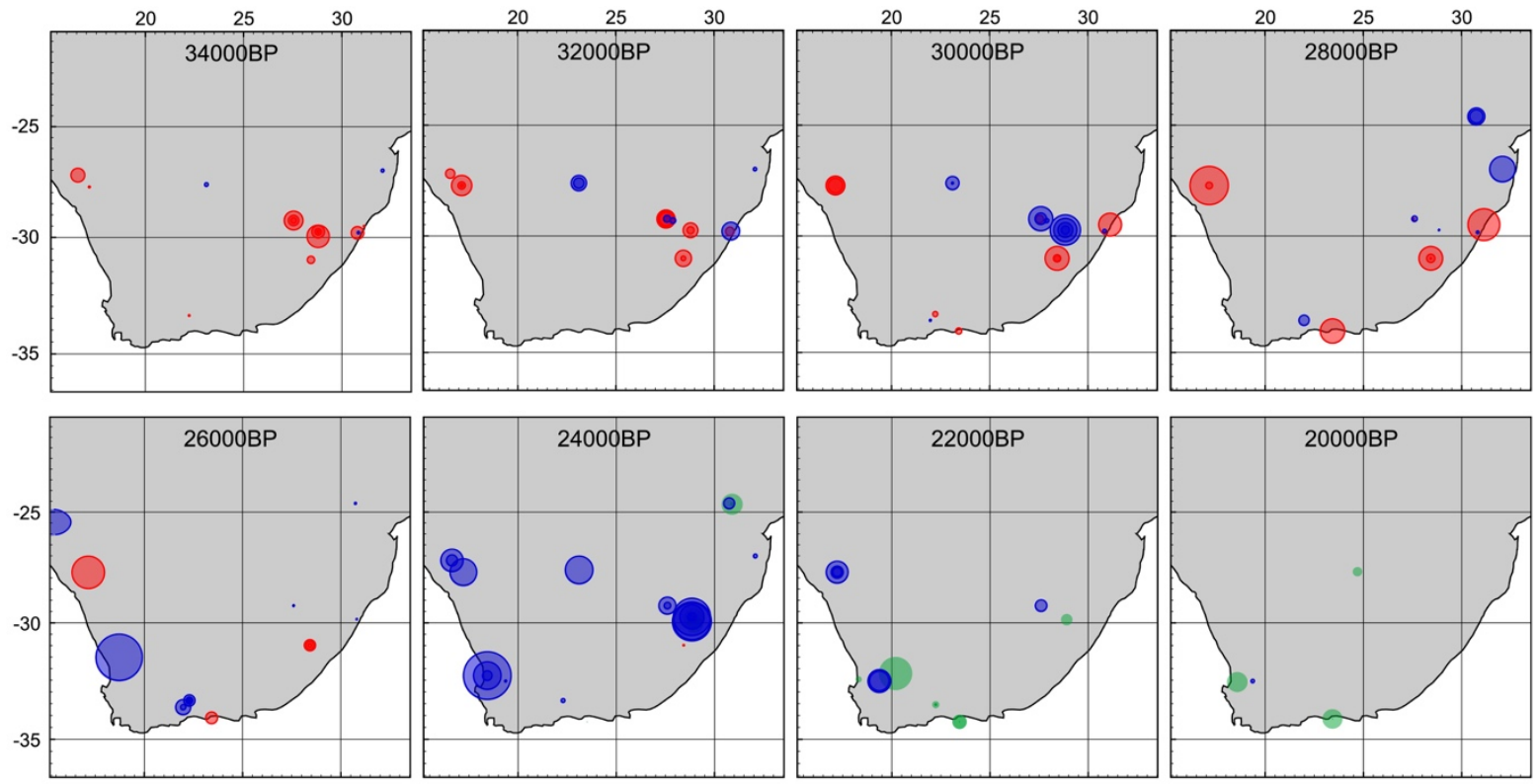